\title{
Study on the In-vitro Culture Method for Normal Embryonic Cell Development of Porcine Parthenogenetic Embryos
}

\author{
Na-Hyeon Jung ${ }^{1, \#}$, Sang-Hwan Kim ${ }^{2, \#}$, Dae-Seung Kim ${ }^{1}$ and Jong-Taek Yoon ${ }^{2,3, *}$ \\ ${ }^{1}$ Major in the Animal Biotechnology, Graduate School of Future Convergence Technology, Hankyong National \\ University, Anseong 17579, Korea \\ ${ }^{2}$ Institute of Genetic Engineering, Hankyong National University, Anseong 17579, Korea \\ ${ }^{3}$ Department of Animal Life Science, Hankyong National University, Anseong 17579, Korea
}

Received March 12, 2020

Revised March 14, 2020

Accepted March 16, 2020

\section{*Correspondence \\ Jong-Taek Yoon \\ E-mail: jtyoon@hknu.ac.kr}

ORCID

https://orcid.org/0000-0002-9408-8239

"These authors contributed equally to this work.
ABSTRACT In the early development of parthenogenetic embryo, cytoplasm and nucleic acid fragmentation may be a cause of lower embryo development. The purpose of this study was to evaluate whether embryonic development and apoptosis factors can be reduced by controlling the in-vitro culture environment by the addition of hormones, pregnancy serum and uterine milk. Our study showed that the activity of Casp-3 increased within the cytoplasm when artificially used hormones to induce the incubation environment, and PCNA's manifestation was low. However, the addition of pregnant serum appeared to lower the Casp-3 activity compared to the other groups. In addition, MMP-9 activity was increased and early embryo development and cytoplasmic fidelity were also increased. Therefore, the results of the present study showed that the use of gestational serum in the development of parthenogenetic embryo inhibit apoptosis and increases cytoplasmic reorganization by natural environmental control in in vitro culture.

Keywords: apoptosis, cell division, extracellular matrix, parthenogenetic, porcine

\section{INTRODUCTION}

Studies of the parthenogenetic embryo can maintain the female's own genetic characteristics, in addition, it is used as an important data in various fields such as cytoplasmic activity, production of autologous stem cells, and mitochondrial action (Azuma et al., 2002; Yeo et al., 2014; Son et al., 2015; Park et al., 2016). The occurrence of Parthenogenetic embryo is known to be activated by combining the polar bodies of mature oocytes by chemical or physical methods, and is produced by increasing free $\mathrm{Ca}+$ to induce cytoplasm activity or by fusion the nucleus by electrical stimulation (Ma et al., 2005; Yi and Park, 2005). Especially, the study of the maintenance of cytoplasmic skeleton due to the activity of cytochalasin $\mathrm{B}(\mathrm{CB})$ in parthenogenesis process is very important for the study of the maintenance of cytoplasm activity after nuclear binding and binding (Kaufman, 1983; Bing et al., 2003). However, when embryonic cells in parthenogenetic embryos developmental, errors in cell division occur during nuclear binding or in vitro culture.

Particularly, as a characteristic of parthenogenesis, the lack of paternal inheritance does not function normally in the formation of genomic imprinting, which causes prob- 
lems in the remodeling of the nuclear membrane during nuclear fission, which appears as a nuclear decay or increases the programmed cell death (Hajjari and Jahani, 2014; Costa et al., 2016; Park et al., 2016). The process of apoptosis is very important in embryonic development. In particular, normal apoptosis acts to increase the subspace during embryonic cell division or to eliminate problems associated with nucleic acid decay (Pawar et al., 2014).

However, the process of erroneous apoptosis seems to increase of metabolic inability and abnormal division in the early 4-8 cell phase embryonic development period, and increase the DNA fragmentation phenomenon, thereby inhibiting the cytoplasmic role by cytotoxic action (Presicce and Yang, 1994; Lee et al., 2011). As a method of solving this problem, it is suggested that the apoptosis can be regulated by presenting a culture method using a serum or a serum replacement method (Kim and Yoon, 2019), but there is little research on the control of apoptosis by applying this method to the parthenogenetic embryos. As a way to increase the process of embryonic cell division, general methods include the addition of appropriate levels of hormones, antioxidants, and the use of substances to control the uterine environment, and other methods suggest the use of pregnant serum and uterine milk (Hafez and Hafez, 2006; Marques et al., 2007; Zeyneloğlu et al., 2011).

In particular, pregnant serum and uterine milk are known to control the environment required for basic metabolism and maintain cytokine activity during embryonic development. However, little research has been conducted to determine whether environmental changes caused by these additives are involved in the control of cell physiology and cell death. Therefore, this study was intended to analyze whether the culture environment control is related to the remodeling of cytoplasm in the development of parthenogenetic embryos.

\section{MATERIALS AND METHODS}

\section{Chemicals and animal ethics statement}

All chemicals used in this study were purchased from the Sigma-Aldrich Chemical Company (St. Louis, MO, USA), unless otherwise stated. This study was carried out in strict accordance with the recommendations in the Guide for the Care and Use of Laboratory Animals of the National Institutes of Health. The protocol was approved by the Committee on the Ethics of Animal Experiments of Hankyong National University (Permit Number: 2018, 2018-002).

\section{In vitro maturation}

Porcine ovaries were collected at local abattoirs (DODRAM, Ansoung, Korea) and transported to the laboratory in $0.9 \%$ physiological saline (with Penicillin G 100 $\mathrm{IU} / \mathrm{mL}$, Streptomycin $100 \mu \mathrm{g} / \mathrm{mL}$ ) at $37^{\circ} \mathrm{C}$ within $2 \mathrm{hr}$ of slaughter. Cumulus-oocyte complexes (COC) were aspirated from surface ovarian follicles 3-6 $\mathrm{mm}$ in diameter using an 18-gauge needle attached to a $10-\mathrm{mL}$ disposable syringe. The supernatant was removed and the precipitate washed three times in a wash medium containing Hepesbuffered tissue culture medium 199 (TCM-199), $10 \mu \mathrm{L} / \mathrm{mL}$ antibiotic and $0.3 \%(\mathrm{w} / \mathrm{v})$ bovine serum albumin (BSA). Selected COCs were transferred to $500 \mu \mathrm{L}$ of IVM medium, which was supplemented with $10 \%$ (v/v) FBS, $15 \mathrm{ng} / \mathrm{mL}$ epidermal growth factor (EGF), $10 \mathrm{IU} / \mathrm{mL}$ pregnant mare serum gonadotropin 199 (PMSG) and human chorionic gonadotropin (hCG), and $30 \mu \mathrm{g} / \mathrm{mL}$ kanamycin for 20-22 hours. After maturation with hormones, COCs were incubated in hormone-free IVM medium at $39^{\circ} \mathrm{C}$. for an additional 21-22 hours in humidified air containing $5 \% \mathrm{CO}_{2}$.

\section{Parthenogenetic activation}

After a 44 hours IVM period, oocytes were released from follicle cells by treatment with $0.1 \%$ hyaluronidase. The removed oocytes were washed several times in an activation solution (0.28 M D-mannitol, $0.1 \mathrm{mM} \mathrm{MgSO}{ }_{4}, 0.05$ $\mathrm{mM} \mathrm{CaCl}{ }_{2}$ and $0.01 \% \mathrm{BSA}$ ) and then activated with a direct current chemical stimulus at $7 \mathrm{~min}$ using $7 \%$ ethanol. After oocytes activation was induced for 2 hours in $2 \mathrm{mM}$ 6-DMAP (6-dimethylaminopurine), and then stabilized by incubating for 4 hours in $2 \mathrm{Mm}$ H-DSOF (HEPES-buffered synthetic oviduct fluid) to promote cell development.

\section{In vitro culture}

For experiments using in-vitro culture, we prepared three types of in-vitro culture media: NC gropu medium is the NCSU-23 medium (North Carolina State University 23 medium) contained 10\% FBS (Petters and Wells 1993), PS group medium is the NCSU-23 medium contained $10 \%$ Pregnancy serum (Cow blood serum after 30 days of pregnancy), EP group medium is the NCSU-23 medium contained $10 \%$ FBS with $2 \mathrm{IU} / \mathrm{mL}$ E2 and $5 \mathrm{IU} / \mathrm{mL}$ proges- 
terone, and UM group medium is the NCSU-23 medium contained 10\% FBS with Uterus milk (Porcine uterus milk after 10 day during estrus). Ten zygotes were added to 30 $\mu \mathrm{L}$ drop of each type of prepared medium and covered with mineral oil, incubated at $39^{\circ} \mathrm{C}$. for 4 days in $5 \% \mathrm{CO}_{2}$, humid atmosphere. The zygotes were incubated for 3 days, then transferred to freshly prepared culture medium. Subsequently, cell division rates were evaluated on culture days 2, 3 and 4, respectively (Visual analysis was performed according to the methods of Alikani et al. (1999) and Mateusen et al. (2005)).

\section{Enzyme linked immunosorbent assay}

For ELISA, total protein was extracted from parthenogenesis embryo using Pro-Prep solution (Intron) according to the manufacturer's instructions. Total protein was quantified using the Bradford Protein Assay Kit (Bio-Rad). For quantification of specific proteins from culture medium and cellular proteins, samples diluted in assay buffer were used to coat a 96-well ELISA plate overnight at $4^{\circ} \mathrm{C}$. MT1-MM (sc-30074, Santa Cruz Biotechnology Inc., Texas, USA), MMP-2 (ab78796-100, Abcam, Cambridge, UK) and MMP-9 (sc-13520, Santa Cruz Biotechnology Inc., Texas, USA) primary antibodies were added to 96-well ELISA plates to analyze the expression levels these proteins in protein sample and culture media; incubation was conducted at $4^{\circ} \mathrm{C}$ for 24 hours. After washing twice with wash buffer $(1 \times$ PBS containing $2.5 \%$ Triton X-100), well contents were blocked for 24 hours at $4^{\circ} \mathrm{C}$ with $1 \%$ skim milk blocking solution. After washing with wash buffer, anti-rabbit (sc-2054, Santa Cruz Biotechnology, Texas, USA) and anti-mouse (sc-2054 and sc-2031, Santa Cruz Biotechnology, Texas, USA) were added secondary antibodies. Each well, and plate were incubated for 2 hours with detection or substrate solution (R \& D Systems, USA). The reaction was stopped with $1 \mathrm{M} \mathrm{NH}_{2} \mathrm{SO}_{4}$, and absorbency was measured at $450 \mathrm{~nm}$.

\section{Zymography}

Gelatin zymography analysis was performed according to the methods of Kim and Yoon 2019. In vitro culture medium is added to Foz loading buffer $(0.06 \%$ bromophenol, $10 \%$ SDS, $2 \%$ glycerol), left on ice for 5 minutes, and then electrophoresed at $150 \mathrm{~V}$ for 1 hour 30 minutes; A $12 \%$ SDS-PAGE gel containing $100 \mathrm{mg} / \mathrm{mL}$ gelatin A/B was used. The gel was washed twice with reconstruction buffer (2.5\% Triton X-100) for 20 minutes, then placed in a zymography reaction buffer and incubated at $37^{\circ} \mathrm{C}$ for 18 hours. Then, the gels were stained (0.5\% Coomassie Blue R250 (Bio-rad, USA)) for measurement of white band to MMP-2 and MMP-9 activity. Average fold values for all hormones were measured and are expressed as mean \pm standard deviation. Data were analyzed using t-test and generalized linear model method using SPSS Statistics 20 (SPSS, Korea).

\section{Immunofluorescence}

Immunofluorescence analysis was performed according to the methods of Kim and Yoon 2019. Each samples were fixed in $4 \%$ paraformaldehyde overnight at $4^{\circ} \mathrm{C}$, af ter, washed for $20 \mathrm{~min}$ in $1 \mathrm{xPBS}$, and permeabilized with $0.2 \%$ Triton $\mathrm{X}-100$ for $30 \mathrm{~min}$ at room temperature (RT). And blocking with 3\% BSA in PBS, the samples were incubated with an antibody against the active forms of Casp-3 (ab4051, abcam, Combridge, UK) and PCNA (sc-7907, Santa Cruz Biotechnology Inc., Texas USA) at $1: 200$ dilutions. The samples were then washed and incubated with antirabbit (35560) and anti-mouse IgG (A11001) conjugated to Alexa Fluor 488 or Alexa Fluor 594 (Molecular Probes: Invitrogen, Ontario Canada). Nuclei were counterstained with $1 \mathrm{~g} / \mathrm{mL}$ Hoechst 33258, and cover slips were mounted using fluorescent mounting medium (Dako, Carpinteria, $\mathrm{CA})$. Images were acquired using an Olympus AX70 fluorescence microscope fitted with a CCD color camera.

\section{RESULTS}

\section{Differences of embryonic cell development in each in vitro culture method}

Table 1 and Fig. 1 shows the results of analyzing the difference of early embryonic development and cytoplasm up to 8 cell stages according to each in vitro culture

Table 1. Result of early development from the parthenogenetic embryos

\begin{tabular}{lcccc}
\hline Group & No. of oocyte & $\geq$ 2-cell (\%) & $\geq$ 4-cell (\%) & $\geq$ 8-cell (\%) \\
\hline NC & 152 & $48(31.58)^{*}$ & $24(15.79)^{* *}$ & $5(3.29)$ \\
EP & 174 & $11(6.32)$ & $7(4.02)$ & $4(2.3)$ \\
PS & 200 & $71(35.5)^{* *}$ & $26(13.0)^{*}$ & $10(5.0)$ \\
UM & 190 & $28(14.74)$ & $16(7.37)$ & $5(2.63)$ \\
\hline
\end{tabular}

NC: FBS, EP: estradiol and progesterone treatment group, PS: bovine pregnancy serum, UM: uterus milk. ${ }^{* * * *}$ : Different letters within same column represent a significant difference $(p<0.05)$. 

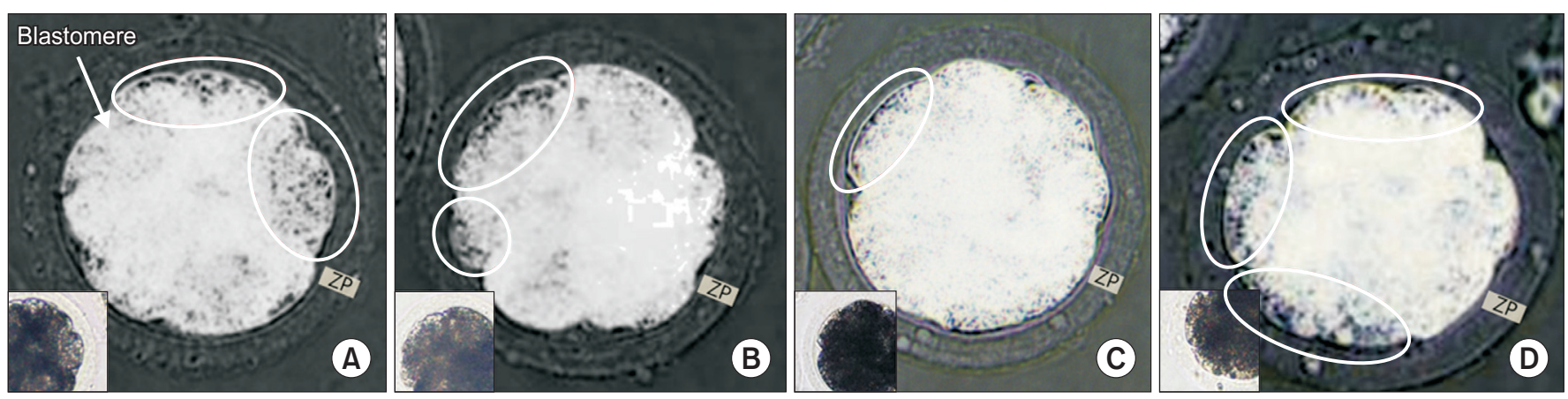

Fig. 1. Development and cytoplasm quality of parthenogenetic embryo. In this figure, applied different filter. (A) FBS group, (B) Estradiol and progesterone treatment group, (C) Bovine pregnancy serum of pregnancy about 30 day, (D) Uterus milk of estrus cycle on 15 day. ZP: Zona pellucida, White round: degradation of cytoplasm $(\times 200)$.
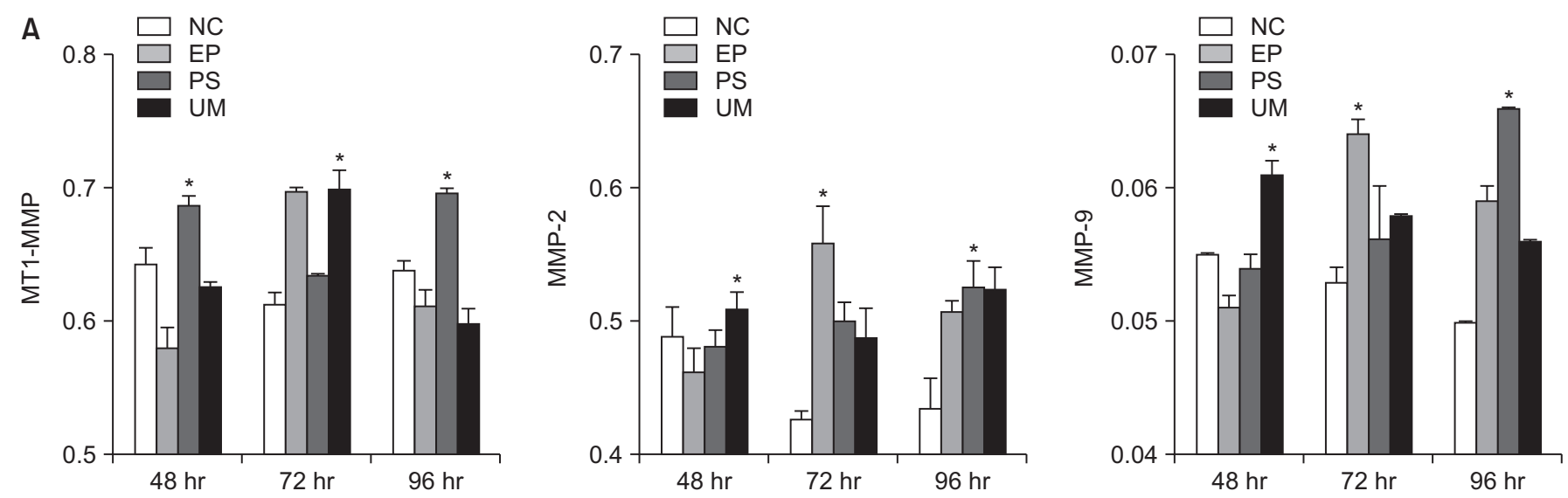

B

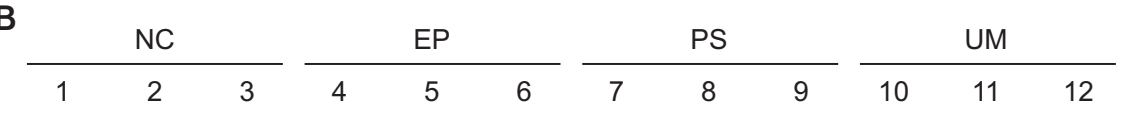

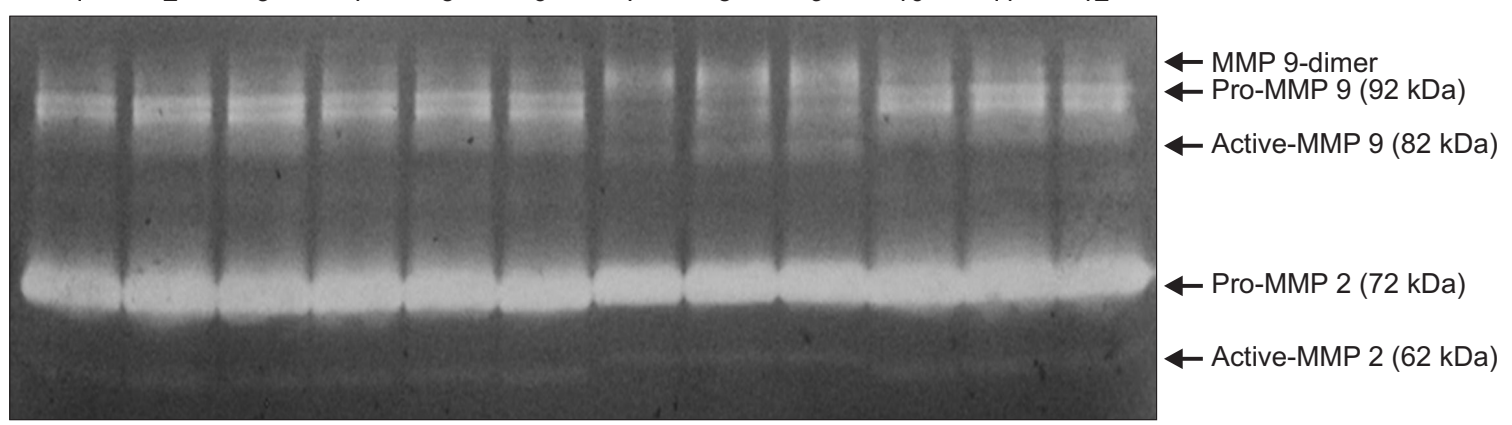

Fig. 2. Analysis of matrix metalloproteinase (MMP) expression and activity in culture medium. (A) ELISA analysis, (B) Gelatin zymography analysis. NC: FBS group, EP: estradiol and progesterone treatment group, PS: bovine pregnancy serum of pregnancy on 30 day, UM: uterus milk of estrus cycle on 15 day.

group. Development up to the early four-cell stage was significantly higher in the NC and PS groups than in the other groups. However, the EP group with hormones was significantly lower. Development analyses of more than 8-cell stages were not able to identify higher development overall, but relatively higher cell division was measured in PS groups than in other groups. The results of analyzing the density of cytoplasm showed that PS group had the least cellular fidelity and fat distribution compared to other counties, and the cytoplasmic expansion due to the expansion of the zona-pellucida increased. 


\section{Activity of MMPs according to embryonic cell development}

The results of analysis of the expression and activity of MMPs affecting the extracellular matrix are shown in Fig. 2. As a result of analyzing the expression patterns of MMPs in embryo culture period of 8 cell or more stages, the activity of MT1-MMPs, which induces MMPs activity, varied with culture time. In particular, this factor increased significantly after $48 \mathrm{~h}$ and $96 \mathrm{~h}$ for NC and PS, but was very higher at $72 \mathrm{~h}$ for NC and PS. In comparison, the incidence of MMP-2 increased somewhat in the EP, but very high in PS for MMP-9; active analysis of MMPs showed polymorphic patterns in the PS group; activeMMP-2 activity did not differential in all groups; however, the activity of MMP-9 was relatively higher in PS.

\section{Analysis of expression and localization of genes related to cell division and apoptosis.}

Fig. 3 shows the results of analyzing the position of expression of each marker in 8 cell-stages. The expression of Casp-3, apoptosis factor, was expressed in the cytoplasm of all treatment groups. The expression of Casp3 was the highest in EP and the lowest in NC. In the case of PS group, there was expression in the extracellular

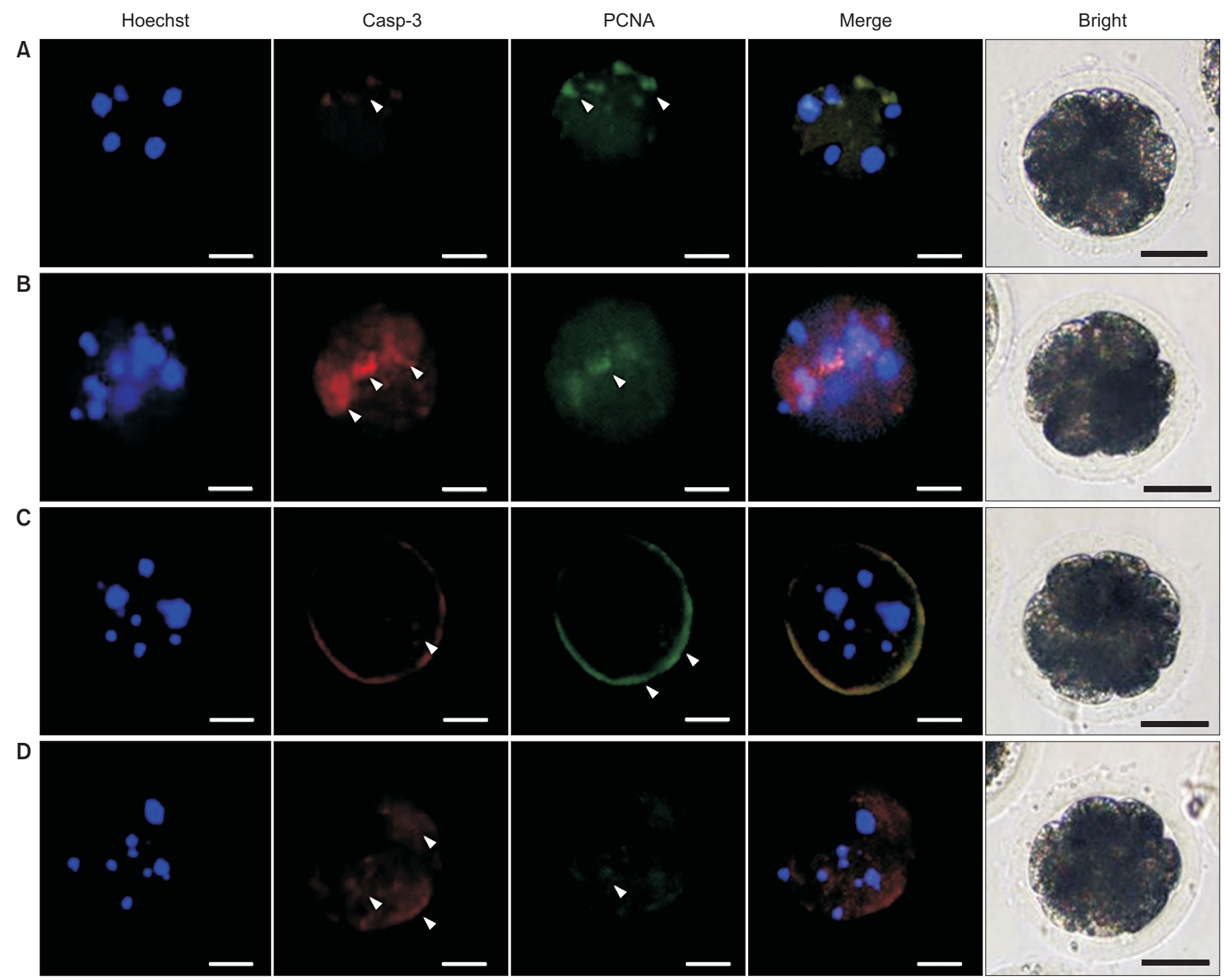

Fig. 3. Expression site and surface analysis of Casp-3 and PCNA in parthenogenetic embryo. (A) FBS group, (B) Estradiol and progesterone treatment group, (C) Bovine pregnancy serum of pregnancy on 30 day, (D) Uterus milk of estrus cycle on 15 day. White arrow is gene expression points (bar $=50 \mu \mathrm{m})$. 
matrix, and expression in the cytoplasm was very lowly. In comparison, EP and UM showed high expression in the cytoplasm. PCNA proteins showed the opposite result to Casp-3 expression, and the expression was very high outside the cytoplasm of PS, but EP and UM groups were relatively lowly.

\section{DISCUSSION}

As a problem with the development of parthenogenetic embryos, research reports have shown that in the early embryonic development, the process of cell metabolism and apoptosis in the cytoplasm decay and nucleic acid differentiation is increased, thereby inhibiting the development of cells (Zhao et al., 2009; Diao et al., 2013a, 2013b; Costa et al., 2016). Especially, the cause of this action can be seen as the main factor in vitro culture. Particularly, in parthenogenetic embryos, the action of paternal inheritance does not occur, which leads to the induction of cytoplasmic starvation during the early embryonic development process (Costa et al., 2016), thereby increasing the apoptosis. In other words, the use of serum in the culture environment can be considered to play a very important role in the development of embryos. As shown by Kim and Yoon 2019, the use of serum seems to control the apoptosis process compared to serum free (Son et al., 2008; Moon et al., 2009). However, the results of this study suggest that the addition of hormones or other substances to the serum medium may affect the maturation and cellular development of the early embryo. This result shows that there is a difference depending on the action of various hormones in the assimilation process of the environment (McCullough et al., 2012; Contrò et al., 2015). Our study found that the environmental action by E2 and progesterone hormone may inhibit some apoptosis, but E2 and Progesterone seems to increase cell death in serum culture medium, and is thought to have no effect on early embryo development. These results suggest that environmental induction by progesterone induced by a certain level of E2 does not affect parthenogenetic embryos development (Bae et al., 2013). As a result of supporting this, in the EP, an increase in MT1-MMPs at $72 \mathrm{~h}$ and a decrease in PCNA at $96 \mathrm{hr}$ may cause problems in embryo development A study by Rossant and Tam 2017 suggested that the addition of hormones in the environment of the womb in pregnancy can promote cell differ- entiation by cytokine activity, but our study suggests that artificial hormonal action increases cell death (Contrò et al., 2015). In addition, the results of control the culture environment by adding pregnant serum and uterine milk could give another opinion on the physiological remodeling of cells (Won et al., 2008; Park et al., 2009). The use of uterine milk seems to lower the development of the embryo, rather increase the apoptosis and induce the abnormal action of the cytoplasm compared to the addition of artificial hormones. However, the use of gestational serum increases MMP-9, which is directly involved in cytoplasmic remodeling, and seems to expand PCNA, which acts during cell differentiation, in the cytoplasm. In other words, the results of this study suggest that the artificial environment regulation by hormones in the development of parthenogenetic embryos may increase the lack of major factors for subspace and nucleic remodeling during embryonic development. In contrast, the use of pregnancy serum suggests that a natural culture environment system can be induced to promote embryonic cytoplasmic activity and differentiation.

\section{CONFLICTS OF INTEREST}

No potential conflict of interest relevant to this article was reported.

\section{AUTHOR CONTRIBUTIONS}

Conceptualization; SH Kim, NH Jung, JT Yoon. Data curation: NH Jung, SH Kim. Formal analysis: SH Kim, NH Jung, DS Kim. Funding acquisition: JT Yoon. Investigation: SH Kim, DS Kim. Methodology: SH Kim, NH Jung, DS Kim. Project administration: SH Kim, JT Yoon. Resources: SH Kim, JT Yoon. Supervision: JT Yoon. Roles/ Writing - original draft: SH Kim, NH Jung. Writing - review \& editing: SH Kim, JT Yoon.

\section{AUTHOR'S POSITION AND ORCID NO.}

NH Jung, Student, https://orcid.org/0000-0003-3073-960X SH Kim, Ph.D., https://orcid.org/0000-0003-0996-6912

DS Kim, Student, https://orcid.org/0000-0002-5740-9136 
JT Yoon, Professor,

https://orcid.org/0000-0002-9408-8239

\section{REFERENCES}

Alikani M, Cohen J, Tomkin G, Garrisi GJ, Mack C, Scott RT. 1999. Human embryo fragmentation in vitro and its implications for pregnancy and implantation. Fertil. Steril. 71:836842.

Azuma T, Kondo T, Ikeda S, Imai H, Yamada M. 2002. Effects of EDTA saturated with Ca2+ (Ca-EDTA) on pig, bovine and mouse oocytes at the germinal vesicle stage during maturation culture and the involvement of chelation of $\mathrm{Zn} 2+$ in pronuclear formation induction by Ca-EDTA. Reproduction 124:235-240.

Bae HK, Kim SH, Lee SY, Hwang IS, Park CK, Yang BK, Cheong HT. 2013. Effect of antioxidant treatment during parthenogenetic activation procedure on the reactive oxygen species levels and development of the porcine parthenogenetic embryos. Reprod. Dev. Biol. 37:51-55.

Bing Y, Che L, Hirao Y, Takenouchi N, Rodríguez-Martínez H, Nagai T. 2003. Parthenogenetic activation and subsequent development of porcine oocytes activated by a combined electric pulse and butyrolactone I treatment. J. Reprod. Dev. 49:159-166.

Contrò V, Basile JR, Proia P. 2015. Sex steroid hormone receptors, their ligands, and nuclear and non-nuclear pathways. AIMS Mol. Sci. 2:294-310.

Costa R, Carneiro BA, Tavora F, Pai SG, Kaplan JB, Chae YK, Chandra S, Kopp PA, Giles FJ. 2016. The challenge of developmental therapeutics for adrenocortical carcinoma. Oncotarget 7:46734-46749.

Diao YF, Kenji N, Han RX, Lin T, Oqani RK, Kang JW, Jin DI. 2013b. Effects of trichostatin A on in vitro development of porcine parthenogenetic and nuclear transfer embryos. Reprod. Dev. Biol. 37:57-64.

Diao YF, Naruse KJ, Han RX, Li XX, Oqani RK, Lin T, Jin DI. 2013a. Treatment of fetal fibroblasts with DNA methylation inhibitors and/or histone deacetylase inhibitors improves the development of porcine nuclear transfer-derived embryos. Anim. Reprod. Sci. 141:164-171.

Hafez ESE and Hafez B. 2006. Reproduction in farm animals. 7th ed, Wiley-Blackwell, Ames, pp. 68-81.

Hajjari M and Jahani MM. 2014. H19: a long non-coding RNA with different roles in cancer progression. Gene Ther. Mol. Biol. 16:172-181.

Kaufman MH. 1975. The experimental induction of parthenogenesis in the mouse. In: Balls M, Wild AE (Eds.), The Early Development of Mammals: the Second Symposium of the British Society for Developmental Biology. Cambridge University Press, Cambridge, pp. 25-44.

Kim SH and Yoon JT. 2019. Effect of serum-containing and serum-free culture medium-mediated activation of matrix metalloproteinases on embryonic developmental compe- tence. Czech J. Anim. Sci. 64:473-482.

Lee SE, Hwang KC, Sun SC, Xu YN, Kim NH. 2011. Modulation of autophagy influences development and apoptosis in mouse embryos developing in vitro. Mol. Reprod. Dev. 78:498-509.

Ma SF, Liu XY, Miao DQ, Han ZB, Zhang X, Miao YL, Yanagimachi R, Tan JH. 2005. Parthenogenetic activation of mouse oocytes by strontium chloride: a search for the best conditions. Theriogenology 64:1142-1157.

Marques MG, Nicacio AC, de Oliveira VP, Nascimento AB, Caetano HV, Mendes CM, Mello MR, Milazzotto MP, Assumpção ME, Visintin JA. 2007. In vitro maturation of pig oocytes with different media, hormone and meiosis inhibitors. Anim. Reprod. Sci. 97:375-381.

Mateusen B, Van Soom A, Maes DG, Donnay I, Duchateau L, Lequarre AS. 2005. Porcine embryo development and fragmentation and their relation to apoptotic markers: a cinematographic and confocal laser scanning microscopic study. Reproduction 129:443-452.

McCullough LE, Eng SM, Bradshaw PT, Cleveland RJ, Teitelbaum SL, Neugut AI, Gammon MD. 2012. Fat or fit: the joint effects of physical activity, weight gain, and body size on breast cancer risk. Cancer 118:4860-4868.

Moon HJ, Shim JH, Hwang IS, Park MR, Kim DH, Ko YG, Park CK, Im GS. 2009. Effects of FBS(fetal bovine serum) and $\mathrm{pFF}$ (porcine follicular fluid) on in vitro maturation and development of porcine parthenogenetic and nuclear transfer embryos. Reprod. Dev. Biol. 33:85-91.

Park JH, Kwon DJ, Lee BK, Hwang IS, Park CK, Yang BK, Cheong HT. 2009. Comparison of microtubule distributions between somatic cell nuclear transfer and parthenogenetic porcine embryos. Reprod. Dev. Biol. 33:13-18.

Park MR, Im JH, Chung HJ, Kim KW, Byun SJ, Hwang SS, Im GS. 2016. Effects of CD26 in parthenogenetically activated porcine embryos. J. Embryo Transf. 31:319-322.

Pawar S, Hantak AM, Bagchi IC, Bagchi MK. 2014. Minireview: steroid-regulated paracrine mechanisms controlling implantation. Mol. Endocrinol. 28:1408-1422.

Petters RM and Wells KD. 1993. Culture of pig embryos. J. Reprod. Fertil. Suppl. 48:61-73.

Presicce GA and Yang X. 1994. Parthenogenetic development of bovine oocytes matured in vitro for $24 \mathrm{hr}$ and activated by ethanol and cycloheximide. Mol. Reprod. Dev. 38:380-385.

Rossant J and Tam PPL. 2017. New insights into early human development: lessons for stem cell derivation and differentiation. Cell Stem Cell 20:18-28.

Son JM, Lee DS, Lee ES, Cho JK, Shin ST. 2008. Effect of porcine serum as macromolecule on the meiotic maturation and embryonic development of porcine oocytes. J. Embryo Transf. 23:93-100.

Son JY, Kim SH, Jung DW, Ryu CY, Yoon JT. 2015. Expression analysis of programmed cell death genes in porcine parthenogenesis. J. Embryo Transf. 30:239-248.

Won CH, Park SK, Kim KY, Roh SH. 2008. Existence of amino acids in defined culture medium influences in vitro devel- 
opment of parthenogenetic and nuclear transfer porcine embryos. J. Embryo Transf. 23:245-250.

Yeo JH, Hwang IS, Park JK, Kwon DJ, Im S, Park EW, Lee JW, Park CK, Hwang S. 2014. Transgenic efficiency of FoxN1targeted pig parthenogenetic embryos. J. Embryo Transf. 29:339-344.

Yi YJ and Park CS. 2005. Parthenogenetic development of porcine oocytes treated by ethanol, cycloheximide, cytochalasin B and 6-dimethylaminopurine. Anim. Reprod. Sci. 86:297-
304.

Zeyneloğlu H, Kahraman S, Pirkevi C. 2011. Co-culture techniques in assisted reproduction: history, advances and the future. J. Reprod. Stem Cell Biotechnol. 2:29-40.

Zhao J, Ross JW, Hao Y, Spate LD, Walters EM, Samuel MS, Rieke A, Murphy CN, Prather RS. 2009. Significant improvement in cloning efficiency of an inbred miniature pig by histone deacetylase inhibitor treatment after somatic cell nuclear transfer. Biol. Reprod. 81:525-530. 